\title{
Derivation of Calibration Coefficients for OCM-2 Sensor for Coastal Waters
}

Muniyandi Tholkapiyan, Palanisamy Shanmugam ${ }^{1 *}$, Prakash Chauhan ${ }^{2}$ and Muthusamy Suresh ${ }^{1}$

${ }^{1}$ Department of Ocean Engineering, Indian Institute of Technology Madras, Chennai 600036, India

${ }^{2}$ Space Applications Centre, Indian Space Research Organization (ISRO), Ahmedabad 380015, India

\begin{abstract}
The radiometric calibration coefficients that are required to enhance the preflight calibration coefficients to improve the performance of the Ocean Colour Monitor (OCM-2) onboard the Indian Remote Sensing Satellite (IRS) are determined using in-situ measurements in coastal waters around southern India. These coefficients were applied to OCM-2 data acquired over coastal waters off Point Calimere (Palk Strait) and Gulf of Mannar of the Bay of Bengal, and are compared with similar coefficients included in the SeaDAS software and those provided with OCM-2 data Standard Coefficients (SC). Two atmospheric correction algorithms were used in conjunction with these coefficients to obtain the water-leaving radiances $\left(\mathrm{L}_{w}\right)$ from OCM-2 data, namely the CAAS algorithm and SeaDAS algorithm. An evaluation of the results of these coefficients and atmospheric correction algorithms showed large deviations in $L_{w}$ values derived with the SC (positive deviation) coefficients and SeaDAS (negative deviation) coefficients when applied to OCM-2 data along with the SeaDAS atmospheric correction algorithm. The deviations were less remarkable with new coefficients when the same (SeaDAS) atmospheric correction algorithm was used. However, application all three coefficients to OCM-2 using the CAAS algorithm showed a similar trend but with less deviations with respect to in-situ $L_{w}$ data. The results obtained with the new coefficients showed good agreement with the in-situ water-leaving radiances (except channels $412-443 \mathrm{~nm}$ ). These results suggest that the new calibration coefficients can be used along with the CAAS atmospheric correction algorithm to improve the performance of OCM-2 sensor for quantitative assessments of the various water constituents in coastal waters (including bloom) around India.
\end{abstract}

Keywords: OCM-2; Calibration; Atmospheric correction; Remote sensing; Coastal waters; India

\section{Introduction}

OCEANSAT-2 spacecraft launched on September 23, 2009 by the Indian Space Research Organization (ISRO) carries the Ocean Colour Monitor (OCM-2) sensor, which was designed to provide continuity to the OCEANSAT-1 OCM-1 instrument (launched on 26 May 1999), and to obtain quantitative information of ocean colour variables such as Chlorophyll-a concentration, suspended sediment (SS) concentration, coloured dissolved organic matter (CDOM), diffuse attenuation coefficient and remote sensing reflectance $\left(\mathrm{R}_{\mathrm{rs}}\right)$. OCM-2 sensor provides high resolution data suitable for coastal water applications (see the specifications in Table 1). Apart from the ocean colour information, OCM-2 data will also be useful for studying the aerosol transport and terrestrial bio-sphere. In order to derive various

\begin{tabular}{|l|l|}
\hline Parameters & Specifications \\
\hline IGFOV at nominal altitude $(\mathrm{m})$ & $360 \times 250$ \\
\hline Swath $(\mathrm{km})$ & 1420 \\
\hline No. of spectral bands & 8 \\
\hline Spectral range $(\mathrm{nm})$ & $402-885$ \\
\hline Spectral bands & B1: $404-424 \mathrm{~nm}$ \\
& B2: $431-451 \mathrm{~nm}$ \\
& B3: $476-496 \mathrm{~nm}$ \\
& B4: $500-520 \mathrm{~nm}$ \\
& B5: $546-566 \mathrm{~nm}$ \\
& B6: $610-630 \mathrm{~nm}$ \\
& B7: $725-755 \mathrm{~nm}$ \\
& B8: $845-885 \mathrm{~nm}$ \\
\hline Quantization Bits & 12 \\
\hline Along track steering & \pm 200 \\
\hline Data acquisition modes & Local Area Coverage (LAC) \& Global Area \\
\hline & Coverage (GAC) \\
\hline
\end{tabular}

Source: http://www.ioccg.org/sensors/OCM-2.pdf

Table 1: Major specifications and features of the OCEANSAT-2 OCM (OCM-2). bio-geo-physical products over the ocean, it is important to determine water-leaving radiances $\left(\mathrm{L}_{\mathrm{w}}\right)$ in different bands of OCM-2 with high accuracy. However, determination of the water-leaving radiances can be achieved if the vicarious calibration coefficients and atmospheric correction schemes are available to process OCM-2 data [1,2].

The major portion of the signal recorded by ocean colour sensors is from the contribution of scattering by molecules and particles (aerosols) in the atmosphere (80-90\%). The process of removing the atmospherically scattered signal in order to retrieve the desired ocean colour signal (i.e. water-leaving radiance) is referred to as atmospheric correction [3]. It has been demonstrated in the previous studies that SeaDAS atmospheric correction algorithm provides satisfactory results for clear oceanic waters with uncertainties $<5 \%$ in $\mathrm{L}_{\mathrm{w}}$ and $<35 \%$ in Chlorophyll-a (Chl-a) concentrations from SeaWiFS [4,5]. However, this algorithm breaks down in optically more complex waters where the spatially intense and diverse aerosols, phytoplankton blooms and suspended sediments (SS), and coloured dissolved organic matter $(\mathrm{CDOM})$ interfere with this algorithm to produce large errors. To overcome these problems, a complex water atmospheric correction algorithm scheme (CAAS) was developed and tested on several MODIS-Aqua data, and the results were compared with in-situ data

${ }^{*}$ Corresponding author: P. Shanmugam, Ocean Optics and Imaging Group, Department of Ocean Engineering, Indian Institute of Technology Madras, Chennai, India, Tel: 91-44-2257-4818, E-mail: pshanmugam@iitm.ac.in

Received December 06, 2012; Accepted December 21, 2012; Published December 29, 2012

Citation: Tholkapiyan M, Shanmugam P, Chauhan P, Suresh M (2012) Derivation of Calibration Coefficients for OCM-2 Sensor for Coastal Waters. J Geophys Remote Sensing 1:106. doi:10.4172/2169-0049.1000106

Copyright: (C) 2012 Tholkapiyan M, et al. This is an open-access article distributed under the terms of the Creative Commons Attribution License, which permits unrestricted use, distribution, and reproduction in any medium, provided the original author and source are credited. 
[5]. The CAAS algorithm is found to work well in such complex waters, yielding physically realistic water-leaving radiances (with significantly reduced negative $\mathrm{L}_{\mathrm{w}}$ values), and recovering areas previously flagged out by the SeaDAS algorithm.

The primarygoal of vicariouscalibration, to improve the performance of the OCM-2 sensor, is to compare water-leaving radiances calculated from OCM-2 data with high quality in-situ measurements. These measurements are usually obtained simultaneously with the satellite over flight over test sites which are selected based on certain criteria like horizontal water homogeneity, distance to land, and temporal difference between satellite over flight and in-situ measurements [1]. In this study, several stations in two different test sites are established-one in the Gulf of Manner (GOM) characterized by moderately turbid to clear waters and other in the Palk Strait off Point Calimere along the east coast of Tamil Nadu (southern India) characterized by moderately turbid to highly turbid waters. The later site is also known for phytoplankton blooms that occur particularly in summer. It is important to note that except bloom patches these waters are usually spatially homogeneous (considering an OCM-2 pixel with the $360 \times 250 \mathrm{~m}$ resolution) and are away from the coast line (few kilometers/beyond $5 \mathrm{~m}$ depth contours to avoid the shallow water effects and non-homogeneity)

The objectives of this study are to determine calibration coefficients for OCM-2 sensor based on in-situ measurements from coastal waters of the Gulf of Mannar and off Point Calimere in the Bay of Bengal. The performance of these coefficients is then compared with that of similar coefficients included in the SeaDAS software and provided with OCM2 data Standard Coefficients (SC). The SeaDAS and CAAS atmospheric correction algorithms are used for atmospheric correction of OCM2 data collected simultaneously with the ship-borne measurements. Results of applying vicarious calibration coefficients to obtain $\mathrm{L}_{\mathrm{w}}$ account for systematic biases in the atmospheric correction algorithm and changes to the previous calibrating results for OCM-2 sensor.

\section{Data and Methods}

\section{In-situ data}

During 14-22 May 2012, ship-borne radiometric (above-water) measurements were performed with Trios sensors (350-1050 nm spectral range) at several stations covering a wide range of coastal waters in the Gulf of Mannar and off Point Calimere along the coast of Tamil Nadu (southern India) (Figures 1 and 2). These measurements include the total water leaving radiance $\mathrm{tL}_{\mathrm{w}}(\lambda)$, sky radiance $\mathrm{L}_{\mathrm{sky}}(\lambda)$, and downwelling irradiance $\mathrm{E}_{\mathrm{d}}(\lambda)$. The radiance sensors for measuring $\mathrm{tL}_{\mathrm{w}}(\lambda)$, and $\mathrm{L}_{\mathrm{sky}}(\lambda)$ were mounted on a frame and fixed on a Cantilever platform that moved these sensors away from the vessel to avoid perturbation of the in-water radiance field by the ship body (thanks to the Mechanical Engineering Workshop colleagues at IIT Madras
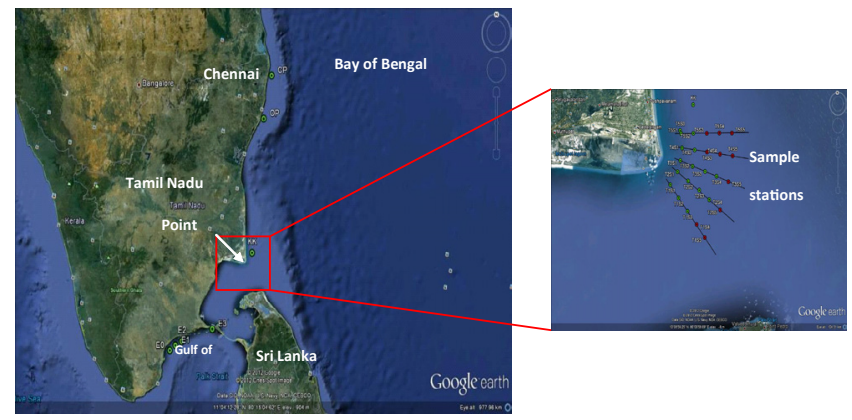

Figure 1: Locations of stations off Point Calimere and in the Gulf of Mannar along the coast of Tami Nadu, Southern India.

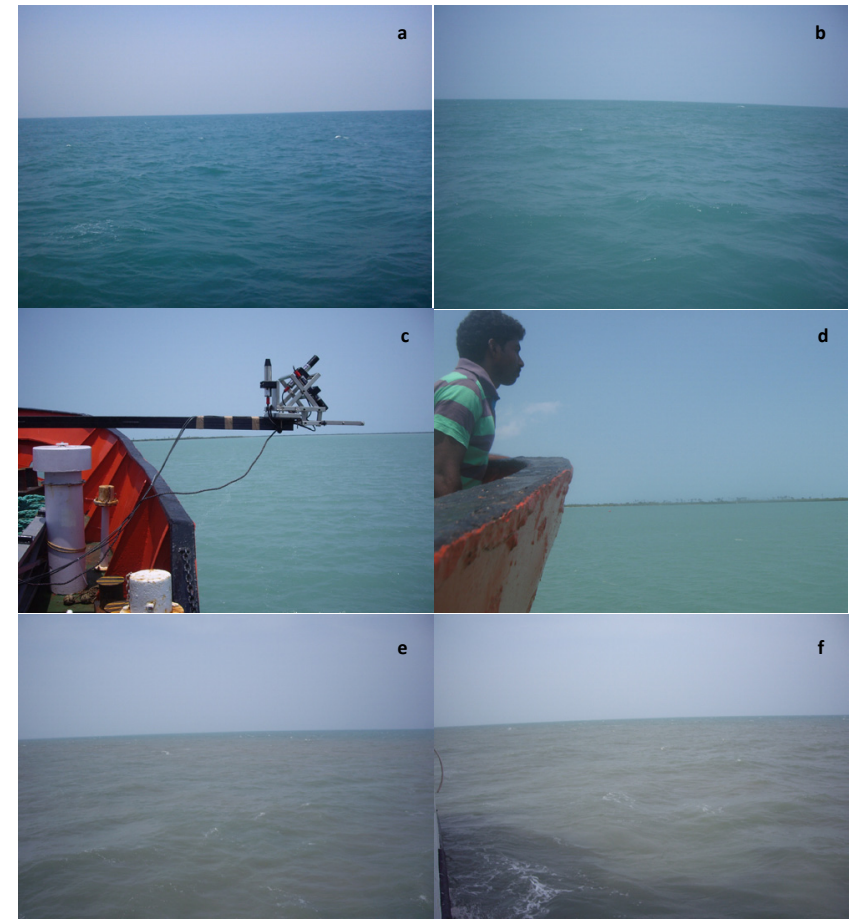

Figure 2: Field photos illustrating the different types (relatively clear to highly turbid) and homogeneity of coastal waters off Point Calimere and in the Gulf of Mannar (considering spatial resolution $360 \times 250 \mathrm{~m}$ of OCM- 2 data). (c) The above-water radiometers are mounted on a frame attached to a Cantilever platform that moves these sensors away from the ship in order to avoid the ship shadow effect and any perturbations.

for making this structure for this application.( Figure 2c). Most of these measurements were made in excellent conditions, near solar noon and under almost cloudless conditions. Since $\mathrm{tL}_{w}(\lambda)$ consisted of the desired water-leaving radiance $\mathrm{L}_{\mathrm{w}}(\lambda)$ and a contamination term $\Delta \mathrm{L}\left(=\mathrm{F}_{\mathrm{r}}(\lambda) \times \mathrm{L}_{\text {sky }}(\lambda)\right.$, it was necessary to make corrections to the recorded data $\left(\mathrm{mWcm}^{-2} \mu \mathrm{m}^{-1} \mathrm{sr}^{-1}\right)$ for the contributions of skylight reflection $\left(\mathrm{L}_{\mathrm{skv}}(\lambda)\right)$ and Fresnel reflectance $\left(\mathrm{F}_{\mathrm{r}}(\lambda)\right)$ of air-sea interface using $\mathrm{L}_{\mathrm{w}}(\lambda)=\mathrm{tL}_{\mathrm{w}}(\lambda)-\Delta \mathrm{L}$. In the above calculation, the values of $\mathrm{L}_{\text {sky }}(\lambda)$ were obtained from the sky radiometer, and the Fr value was assumed to be 0.025 [6]. In fact, Fr varies with viewing geometry, sky conditions and sea surface roughness due to wind and is wavelength-dependent under a cloudy sky [7].

Seawater samples (200-2000 ml) collected simultaneously with radiometric measurements were filtered on Whatman GF/F filters and stored in liquid nitrogen for analysis in the laboratory. After returning to the laboratory, chlorophyll-a was extracted immediately and its concentration was quantified based on the standard method [8] using a Perkin-Elmer Lambda 35 Spectrophotometer. The measured Chl-a concentrations varied from 1.1 to $14 \mathrm{mg} \mathrm{m}^{-3}$. Similarly, seawater samples (200-1000ml) were filtered on Whatman GF/F filters and these filter papers were kept at dark conditions until analysis took place in the laboratory. The suspended sediment concentrations determined based on the simple oven-drying method varied up to $50 \mathrm{gm}^{-3}$. Seawater samples for the determination of absorption coefficients of CDOM were also collected from each station and filtered through 0.45 $\mu \mathrm{m}$ filter papers $(25 \mathrm{~mm})$ previously rinsed with ultra pure Milli-Q water. $50 \mathrm{ml}$ of filtered sample were stored in glass flasks in the dark at $4^{\circ} \mathrm{C}$ for analysis in the laboratory. Immediately after returning to the laboratory, samples for spectroscopic analyses were allowed to warm to room temperature. Absorbance scans from 350 to $900 \mathrm{~nm}$ (at $1 \mathrm{~nm}$ 
sample intervals) were conducted using the same spectrophotometer (but using the $10 \mathrm{~cm}$ optical tubes) connected to a desktop computer, and the absorption coefficients were determined based on the standard procedure [9].

\section{Satellite data}

The OCM-2 Level 1B data products for the study area (Palk Strait and Gulf of Mannar) were obtained from the National Remote Sensing Centre (NRSC) for the cruise period from 14-22 May 2012. Additional OCM-2 data products were also obtained for bloom-dominated waters in the Arabian Sea (for example, 20 Feb. 2010). These data were supplied in HDF format with necessary ancillary information for further processing in order to derive the ocean colour products (Table 2).

\section{Method}

Vicarious calibration is usually achieved by comparing satellitederived $\mathrm{L}_{\mathrm{w}}$ and in-situ measured $\mathrm{L}_{\mathrm{w}}$, but it can also be based on models without field measurements, regional climatology data or retrievals from other sensors. In the absence of any in-situ match-up data, an inter-comparison of satellite sensors can be the best choice. For example, as the MODIS and SeaWiFS instruments are well-calibrated (mainly for clear waters), the SeaDAS $\mathrm{L}_{\mathrm{w}}$ values are the best choice to vicariously calibrate another satellite sensor, particularly when the bands of the sensor to be calibrated (e.g. OCM-2) are nearly identical to these sensors. However, no operational sensors are available today that are identical to OCM-2 for adopting a similar calibration method. Moreover, the present calibration coefficients available for OCM2 sensor are not accurately determined, thereby often producing abnormal water-leaving radiances at many wavelengths. Therefore, new calibration coefficients are needed for the proper calibration and validation of data from OCM-2 sensor.

A complex water atmospheric correction algorithm scheme (CAAS) for providing ocean colour products has been developed and further improved using in-situ data and MODIS-Aqua data $[5,10]$. This algorithm processes the Rayleigh-corrected radiances on a pixel-by-pixel basis to produce water-leaving radiances so that these values for one pixel are completely unrelated to water-leaving radiances from another pixel, thereby potentially avoiding derivation and translation of certain information (e.g. aerosol) from one pixel to another pixel, eliminating any assumptions associated with such correction procedures or ruling out a demand for any in-water models to eliminate the black pixel assumption. Briefly, CAAS algorithm uses the radiance data to perform atmospheric correction as follows: 1) Remove the Rayleigh scattering effects based on a standard method available with the SeaDAS 2) Remove the aerosol scattering effects 3) Remove the sun glint effects and 4) Eliminate the combined effects of aerosol-Rayleigh (coupled term). Finally, CAAS involves an iterative procedure to retrieve water-leaving radiances $\left(\mathrm{L}_{w}\right)$ from $\mathrm{tL}_{\mathrm{w}}(\lambda)$ (diffuse transmittance multiplied by water-leaving radiance) that closely match with in-situ data [5].

Several OCM-2 data, processed for relatively clear to turbid waters using the above approach, often showed abnormally high Rayleigh radiance compared to the total radiance resulting in negative $L_{w}(\lambda)$ values. Adjusting the total radiance values without affecting the their spectral shape might introduce errors in the retrieved $L_{w}(\lambda)$ values using a particular atmospheric correction algorithm. This means that changes in the total radiance would affect the water leaving radiance derived after atmospheric correction. In the present approach, calibration coefficients are determined by comparing the output of water leaving radiance derived using the CAAS atmospheric correction algorithm with in-situ data. This step is iteratively carried out until the consistency between OCM- 2 derived $\mathrm{L}_{\mathrm{w}}(\lambda)$ and in-situ $\mathrm{L}_{\mathrm{w}}(\lambda)$ is reached. This vicarious calibration technique provides the solution to adjust the sensor's TOA radiance to produce more accurate radiance values. The in-situ data collected simultaneously with OCM-2 data are used for this study so that the difference in the OCM-2 and in-situ data set forces to adjust the TOA radiance. The adjustments are verified with a number of OCM-2 data acquired over coastal waters of the Bay of Bengal and Arabian Sea, and the shape of $L_{w}(\lambda)$ spectra is found consistent with in-situ $L_{w}(\lambda)$ data. The new calibration coefficients (Table 3 ) are

\begin{tabular}{|c|c|c|c|c|c|c|c|}
\hline Stations & Date & Time & Latitude & Longitude & Depth (m) & $\begin{array}{l}\text { OCM-2 Satellite Data } \\
\text { Acquisition } \\
(\text { Res. } 360 \times 250 \mathrm{~m})\end{array}$ & $\begin{array}{l}\text { OCM-2 Satellite Data } \\
\text { Acquisition }\end{array}$ \\
\hline St-1 & 16/05/2012 & 12.00 & $9^{\circ} 15.4^{\prime} \mathrm{N}$ & 79012.4'E & 2.5 & $\begin{array}{l}16 / 05 / 2012 \\
(12.02 \text { noon })\end{array}$ & $16 / 05 / 2012$ \\
\hline St-2 & $18 / 05 / 2012$ & 14.30 & $10^{\circ} 10.7^{\prime} \mathrm{N}$ & 80002.69'E & 12.3 & $\begin{array}{l}18 / 05 / 2012 \\
(12.02 \text { noon })\end{array}$ & GOM \& PC \\
\hline St-3 & 18/05/2012 & 11.00 & $10^{\circ} 08.9^{\prime} \mathrm{N}$ & 79058.4'E & 8.3 & $\begin{array}{l}18 / 05 / 2012 \\
(12.02 \text { noon })\end{array}$ & GOM \& PC \\
\hline St-4 & 18/05/2012 & 11.30 & $10^{\circ} 11.1^{\prime} \mathrm{N}$ & $79^{\circ} 56.3^{\prime} \mathrm{E}$ & 06.0 & $\begin{array}{l}18 / 05 / 2012 \\
(12.02 \text { noon })\end{array}$ & GOM \& PC \\
\hline St-5 & 18/05/2012 & 12.20 & $10^{\circ} 13.4^{\prime} \mathrm{N}$ & $79^{\circ} 54.5^{\prime} \mathrm{E}$ & 06.0 & $\begin{array}{l}18 / 05 / 2012 \\
(12.02 \text { noon })\end{array}$ & GOM \& PC \\
\hline St-6 & 18/05/2012 & 13.00 & $10^{\circ} 15.3^{\prime} \mathrm{N}$ & $79^{\circ} 56.26^{\prime} \mathrm{E}$ & 08.0 & $\begin{array}{l}18 / 05 / 2012 \\
(12.02 \text { noon })\end{array}$ & GOM \& PC \\
\hline St-7 & 18/05/2012 & 13.40 & $10^{\circ} 13.7^{\prime} \mathrm{N}$ & $79^{\circ} 58.35^{\prime} \mathrm{E}$ & 09.0 & $\begin{array}{l}18 / 05 / 2012 \\
(12.02 \text { noon })\end{array}$ & GOM \& PC \\
\hline St-8 & 18/05/2012 & 14.30 & $10^{\circ} 13.27^{\prime} \mathrm{N}$ & $80^{\circ} 01.37^{\prime} \mathrm{E}$ & 11.0 & $\begin{array}{l}18 / 05 / 2012 \\
(12.02 \text { noon })\end{array}$ & GOM \& PC \\
\hline St-9 & 18/05/2012 & 15.20 & $10^{\circ} 14.70^{\prime} \mathrm{N}$ & $80^{\circ} 05.16^{\prime} \mathrm{E}$ & 15.0 & $\begin{array}{l}18 / 05 / 2012 \\
(12.02 \text { noon })\end{array}$ & GOM \& PC \\
\hline St-10 & 20/05/2012 & 12.30 & $10^{\circ} 22.02^{\prime} \mathrm{N}$ & $79^{\circ} 57.41^{\prime} \mathrm{E}$ & 06.0 & $\begin{array}{l}20 / 05 / 2012 \\
(12.02 \text { noon) }\end{array}$ & GOM \& PC \\
\hline \multirow{2}{*}{\multicolumn{6}{|c|}{ Additional OCM-2 Images used for Calibration and Validation }} & $\begin{array}{l}14 / 05 / 2012 \\
(12.02 \text { noon })\end{array}$ & GOM \& PC \\
\hline & & & & & & $\begin{array}{l}20 / 02 / 2010 \\
(01.41 \mathrm{pm})\end{array}$ & Arabian Sea \\
\hline
\end{tabular}

Table 2: Details of in-situ data and OCM-2 data. GOM \& PC refers to coastal waters of Gulf of Mannar and Point Calimere. 


\begin{tabular}{|l|l|l|l|l|l|l|l|l|}
\hline Wavelength & $\mathbf{4 1 5}$ & $\mathbf{4 4 2}$ & $\mathbf{4 9 1}$ & $\mathbf{5 1 2}$ & $\mathbf{5 5 7}$ & $\mathbf{6 2 0}$ & $\mathbf{7 4 5}$ & $\mathbf{8 6 5}$ \\
\hline SeaDAS Coefficients & 0.79 & 0.69 & 0.81 & 0.75 & 0.76 & 0.75 & 0.9 & 0.77 \\
\hline SC Coefficients & 0.95 & 0.76 & 0.83 & 0.84 & 0.86 & 0.95 & 0.97 & 1.02 \\
\hline New Coefficients & 0.8 & 0.69 & 0.78 & 0.798 & 0.8 & 0.85 & 0.9 & 0.88 \\
\hline
\end{tabular}

Table 3: Calibration coefficients for processing OCM-2 sensor data.

\begin{tabular}{|l|l|l|l|l|l|l|}
\hline Wavelength & $\mathbf{4 1 5}$ & $\mathbf{4 4 2}$ & $\mathbf{4 9 1}$ & $\mathbf{5 1 2}$ & $\mathbf{5 5 7}$ & $\mathbf{6 2 0}$ \\
\hline \begin{tabular}{l} 
In-situ $\mathrm{L}_{w}$ \\
\hline $\begin{array}{l}\text { SeaDAS } \mathrm{L}_{w} \text { from } \\
\text { SeaDAS Coefficients }\end{array}$
\end{tabular} & $\mathbf{1 . 1 9 4 4 0 9}$ & $\mathbf{1 . 6 0 9 1 9 8}$ & $\mathbf{2 . 3 1 3 6 5}$ & $\mathbf{2 . 3 1 7 3 6 4}$ & $\mathbf{2 . 3 8 5 1 0 1}$ & $\mathbf{1 . 0 5 0 7 6 8}$ \\
\hline $\begin{array}{l}\text { SeaDAS } \mathrm{L}_{w} \text { from SC } \\
\text { Coefficients }\end{array}$ & 3.476111 & -0.16033 & 1.677222 & 1.073778 & 1.637556 & 0.175722 \\
\hline $\begin{array}{l}\text { SeaDAS } \mathrm{L}_{w} \text { from New } \\
\text { Coefficients }\end{array}$ & $\mathbf{1 . 0 3 0 7 7 8}$ & $\mathbf{1 . 5 1}$ & $\mathbf{2 . 5 2 1 3 3 3}$ & $\mathbf{2 . 6 4 9 3 3 3}$ & $\mathbf{2 . 7 3 1 4 4 4 4}$ & $\mathbf{1 . 1 7 2 6 1 1}$ \\
\hline $\begin{array}{l}\text { CAAS } \mathrm{L}_{w} \text { from } \\
\text { SeaDAS } \\
\text { Coefficients }\end{array}$ & 0.358889 & 0.822556 & 2.347 & 1.589222 & 2.049667 & 0.490611 \\
\hline $\begin{array}{l}\text { CAAS L from SC } \\
\text { Coefficients }\end{array}$ & 0.689111 & 1.769889 & 2.900111 & 2.830444 & 3.285556 & 1.266389 \\
\hline $\begin{array}{l}\text { CAAS } L_{w} \text { from New } \\
\text { Coefficients }\end{array}$ & $\mathbf{0 . 4 0 8 4 4 4}$ & $\mathbf{1 . 0 2 3 5 5 6}$ & $\mathbf{2 . 3 6 9 4 4 4}$ & $\mathbf{2 . 4 6 7 4 4 4}$ & $\mathbf{2 . 7 1 7 6 6 7}$ & $\mathbf{0 . 9 2 2 5}$ \\
\hline
\end{tabular}

Table 4: Comparison of in-situ $L_{w}$ measurements (averaged taken over 9 Stations) and OCM-2 derived $L_{w}$ values in coastal waters off Point Calimere and in the Gulf of Mannar of the Bay of Bengal along the coast of Tami Nadu.

applied to OCM-2 data and the results are compared with outputs of the similar calibration coefficients included in the SeaDAS software and those provided with OCM-2 data (SC).. This comparison is made from using the SeaDAS and CAAS atmospheric correction algorithms. The atmospheric correction output of OCM-2 data is validated with in-situ data, and any errors resulting from imperfect atmospheric correction schemes are quantified. It should be noted that the new vicarious calibration coefficients should be applied to the total radiance data (before atmospheric correction) in order to determine the trend of water-leaving radiance derived from the atmospheric correction algorithms.

\section{Results and Discussion}

According to the criteria of horizontal water homogeneity, distance to land, horizontal homogeneity aerosols, and temporal difference between satellite over-flight and in situ measurements, the calibration coefficients were determined and listed in table 3 along with those provided in the SeaDAS software and those provided with OCM-2 data (SC). It should be noted that the aerial extent of sampled waters is much larger than the $360 \mathrm{~m} \times 250 \mathrm{~m}$ spatial resolution of OCM- 2 sensor, thus validating the assumption of spatial homogeneity in this study. On the other hand, radiometric and laboratory data collected for a wide range of such waters are necessary in the calibration and validation exercise so that the calibration coefficients determined from using these data can be extended to similar coastal waters in other regions. The performance of the OCM-2 was improved by applying these coefficients to these data and additional data collected over complex (bloom) waters in the Arabian Sea. The OCM-2 derived $\mathrm{L}_{w}(\lambda)$ values from the SeaDAS and CAAS atmospheric correction algorithms using these coefficients were compared with the in-situ water-leaving radiance measurements (415, $442,491,512,557$ and $620 \mathrm{~nm}$ ) that were collected simultaneously with the OCM-2 data. Though the calibration coefficients were determined for the 745 and $865 \mathrm{~nm}$ channels, the results for these NIR channels were excluded from this analysis because of the OCM-2 derived $L_{w}(\lambda)$ values approaching near-zero values at the NIR wavelengths (mainly relatively clear and in-water bloom waters). In table 3 , the calibration coefficients available in the SeaDAS software are equal or lower (for 415, 442, 512, $557,620,745$ and $865 \mathrm{~nm}$ ) than those of the SC and new calibration coefficients for these channels. A small deviation of the SeaDAS coefficients (slightly higher) exists for $491 \mathrm{~nm}$. Large deviations of the SC coefficients exist for all other channels; i.e. the SC coefficients are much higher than the new coefficients. Thus, it was useful to consider all these three sets of calibration coefficients along with the SeaDAS and CAAS atmospheric correction algorithms to derive $L_{w}(\lambda)$ values from OCM-2 data and compare these data with in-situ measurements in coastal waters.

Table 4 presents the comparison of the in-situ $\mathrm{L}_{w}(\lambda)$ values (averaged for 9 stations from the May cruise) at the first six wavelengths (415-620nm) with those derived from the corresponding OCM-2 data using the three sets of calibration coefficients and two atmospheric correction (CAAS and SeaDAS) algorithms. It is observed that when these calibration coefficients applied with the SeaDAS atmospheric correction algorithm, $\mathrm{L}_{\mathrm{w}}(\lambda)$ values determined from OCM- 2 data based on the new calibration coefficients are much closer to the in-situ $\mathrm{L}_{w}(\lambda)$ values. By contrast, $L_{w}(\lambda)$ values determined by the SC coefficients are much higher than those of the in-situ $\mathrm{L}_{w}(\lambda)$ at all the wavelengths. An inverse trend in $L_{w}(\lambda)$ values determined by the SeaDAS coefficients is observed (i.e., much lower $\mathrm{L}_{w}(\lambda)$ values at all the wavelengths compared with in-situ $\mathrm{L}_{\mathrm{w}}(\lambda)$ values). Similar trends are noticed when the CAAS atmospheric correction algorithm was used to process OCM2 data after calibrated with all three sets of calibration coefficients. Except for 415 and 442 channels, $\mathrm{L}_{w}(\lambda)$ values determined based on the new calibration coefficients match closely with the in-situ $\mathrm{L}_{w}(\lambda)$ values. High $L_{w}(\lambda)$ values are again obaserved with the SC calibration coefficients except for the blue wavelengths, whereas low $\mathrm{L}_{w}(\lambda)$ values are determined by the SeaDAS calibration coefficients (except for 491 $\mathrm{nm}$ ). Shanmugam [9] reported that the CAAS atmospheric correction algorithm produces the relatively lower $L_{w}(\lambda)$ values (compared to insitu $\mathrm{L}_{\mathrm{w}}(\lambda)$ data) for the blue wavelengths (mainly $412 \mathrm{~nm}$ ). Thus, low Lw(412) values determined from OCM-2 data could be caused by this algorithm. However, errors associated with the CAAS algorithm are not as severe as those of the SeaDAS atmospheric correction algorithm (see negative values at 415 and $442 \mathrm{~nm}$ in table 4) in complex waters [9]. According to the results presented in table 4, it should noted that the CAAS derived $L_{w}(\lambda)$ values are more accurate than the SeaDAS derived $\mathrm{L}_{\mathrm{w}}(\lambda)$ values when the new calibration coefficients are used to process OCM-2 data. On the contrary, the SC coefficients produce abnormally high $\mathrm{L}_{\mathrm{w}}(\lambda)$ values and SeaDAS coefficients yield relatively low $\mathrm{L}_{\mathrm{w}}(\lambda)$ values for both the atmospheric correction algorithms. However, errors are significantly minimized when the CAAS atmospheric correction algorithm is used to process OCM-2 data after calibrated with all three sets of coefficients in these coastal waters.

Figure 3 shows an example of the OCM-2 water-leaving radiance image (at $557 \mathrm{~nm}$ ) derived from the new calibration coefficients using CAAS algorithm (mean image for the cruise period from 16-20 May 2011 to avoid clouds in the adjacent areas to the variability of the water properties), in coastal waters along the east-coast of India (left panel) and off Point Calimere and in the Gulf of Mannar along the coast of Tami Nadu (bottom right panel). The grey/dark features in offshore waters are well characterized by much weaker radiances in the green channel, while the brighter features relate to highly reflective materials around the coastal areas of Point Calimere caused by strong radiance in the green channel. The top right panel shows the in-situ waterleaving radiance spectra measured in coastal waters off Point Calimere during 16-20 May 2011. Because of the increased suspended sediment concentrations in these waters, the OCM- 2 derived water-signal peaks towards the green wavelength and shows non-zero values at the nearinfrared channels. Because the quality of the atmospheric correction affects the quality of $L_{w}(\lambda)$ which is key to the estimation of biophysical 


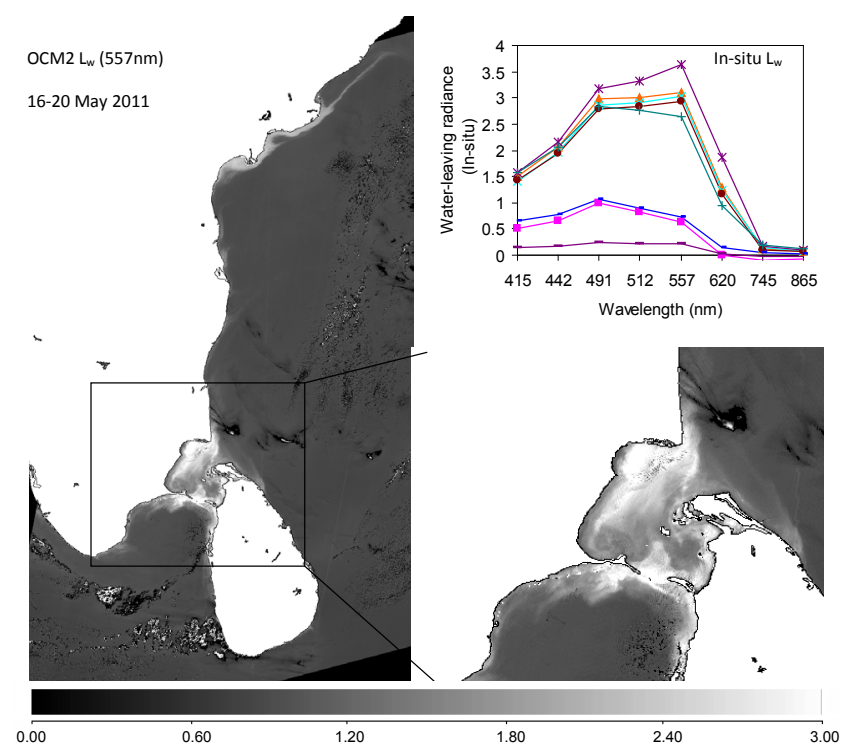

Figure 3: An example of the OCM-2 derived water-leaving radiance map $(557 \mathrm{~nm})$ from the new calibration coefficients and CAAS atmospheric correction algorithm in coastal waters off Point Calimere and in the Gulf of Mannar along the coast of Tami Nadu, Southern India. In-situ water-leaving radiance spectra are shown on the top-right corner panel which is based on several data collected from turbid and relatively clear waters in this area during 16-20 May 2011.
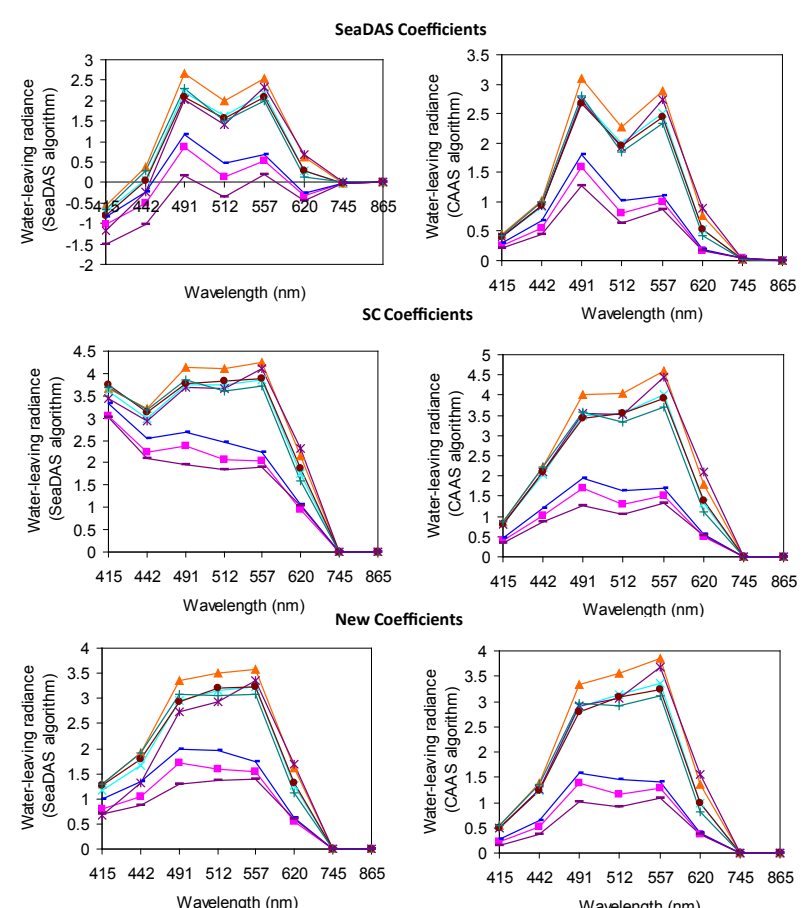

Figure 4: The OCM-2 water-leaving radiance spectra derived from the SeaDAS (left panels) and CAAS (right panels) atmospheric correction algorithms. SeaDAS, SC and new calibration coefficients were used to calibrate OCM-2 data. Note that these spectra were obtained from the corresponding pixels of the in-situ data collected in turbid and relatively clear waters during 16-20 May 2011.

products, OCM- 2 derived $\mathrm{L}_{w}(\lambda)$ values are compared with the in-situ $\mathrm{L}_{\mathrm{w}}(\lambda)$ data (Figure 4$)$. This spectral comparison clearly demonstrates that the SeaDAS atmospheric correction algorithm when applied to calibrated OCM-2 data (with SeaDAS coefficients) produces large anomalous differences in the $\mathrm{L}_{w}(\lambda)$ spectra, i.e. negative $\mathrm{L}_{w}(\lambda)$ values in the blue domain and spectrally distorted $\mathrm{L}_{w}(\lambda)$ in other wavelength domains due to inaccuracy of atmospheric correction over such coastal waters [9]. Negative $L_{w}(\lambda)$ values are vanished when the CAAS atmospheric correction was used to process OCM-2 data calibrated with the same coefficients. Note that the spectral shape is significantly distorted due to the improper calibration coefficients. By contrast, very high $\mathrm{L}_{\mathrm{w}}(\lambda)$ values are observed (in the blue domain and other channels) from OCM-2 data calibrated with the SC calibration coefficients and processed with the SeaDAS atmospheric correction algorithm. The spectral shape of $L_{w}(\lambda)$ is not realistic due to the calibration errors. However, application of the SC calibration coefficients along with CAAS algorithm significantly improves the results (see realistic spectral shape) as shown in figure 4 . When OCM-2 data were calibrated with the new coefficients, the SeaDAS atmospheric correction algorithm tends to yield more realistic $\mathrm{L}_{w}(\lambda)$ spectra (non-zero $\mathrm{L}_{w}(\lambda)$ ) in the bluered wavelength domain, although their values are underestimated at all wavelengths. By contrast, the combination of the new calibration coefficients and CAAS atmospheric correction algorithm work well for the OCM-2 data in terms of successfully removing most atmospheric correction effects and producing non-zero $L_{w}(\lambda)$ values in the bluered wavelength domains (though slight underestimation in the NIR domain). Good agreement between OCM- 2 derived $\mathrm{L}_{w}(\lambda)$ and in-situ $L_{w}(\lambda)$ values implies the suitability of the new calibration coefficients and CAAS algorithm for processing OCM-2 data for coastal water applications.

The comparison of water-leaving radiance derived from OCM2 data using the above calibration coefficients and atmospheric correction algorithms for algal bloom waters in the Arabian Sea are shown in figures $5 \mathrm{a}-\mathrm{c}$. As expected, the SeaDAS atmospheric correction algorithm always delivers negative $\mathrm{L}_{\mathrm{w}}(\lambda)$ values across the wavelengths from 412-745 $\mathrm{nm}$ because of overcorrection of the atmospheric effects (Figure 5a). This is due to the fact that these waters containing dense
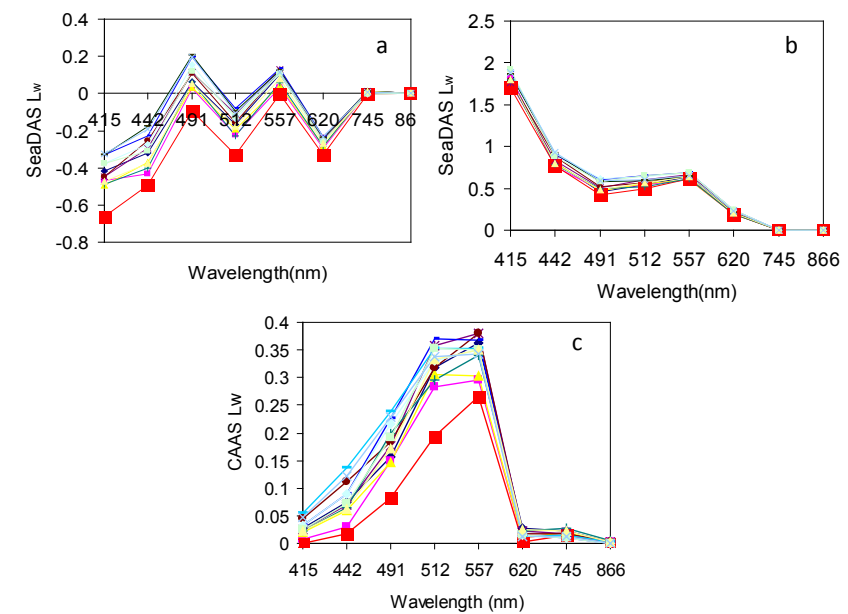

Figure 5: The OCM-2 derived water-leaving radiance spectra for bloomdominated waters in the Arabian Sea. (A and $B$ ) The $L_{w}(\lambda)$ from OCM-2 data calibrated with the SeaDAS and SC calibration coefficients and atmospherically corrected with the SeaDAS algorithm, and $(C)$ The $L_{w}(\lambda)$ from OCM-2 data calibrated with the new calibration coefficients and atmospherically corrected with the CAAS algorithm. Note that these spectra were obtained from several bloom pixels of the OCM-2 image acquired on 20 Feb. 2010. 
phytoplankton blooms had a relatively strong water-leaving radiance in the near-infrared bands and an in-water model with this algorithm for estimating these NIR contributions became highly inadequate to account for these contributions [10]. Furthermore, the inadequacy of aerosol models cannot be ruled out when dealing with these oceanic features in the coastal regions. When such large errors occur in turbid and bloom dominated waters due to excessive aerosol path radiance removal, all pixels containing these features are usually flagged out ultimately limiting ocean colour applications in this region [10]. On the other hand, $\mathrm{L}_{\mathrm{w}}(\lambda)$ values derived from the calibrated and atmospherically corrected OCM-2 data (using SC calibration coefficients and SeaDAS atmospheric correction algorithm) are abnormally high in the blue region and their spectral curves are unrealistic in these bloom waters (Figure 5b). All these results apparently indicate the failure of the calibration coefficients and atmospheric correction algorithm in Arabian Sea waters. By contrast, CAAS algorithm applied with the new calibration coefficients produces more realistic spatial structures in water-leaving radiance maps as well as positive water-leaving radiance for all the visible bands (Figure $5 \mathrm{c}$ ), whereas the other two sets of calibration coefficients show increasing errors in the blue-green wavelength domains that limit the practical utility of OCM-2 data in Arabian Sea waters.

To illustrate the differences between OCM-2 derived $\mathrm{L}_{\mathrm{w}}(\lambda)$ and in-situ $\mathrm{L}_{w}(\lambda)$ data, scatterplots of the OCM-2 derived water-leaving radiance (for SeaDAS, SC and new calibration coefficients) from the SeaDAS atmospheric correction algorithm are shown in Figure 6. It is clearly seen that $\mathrm{L}_{w}(\lambda)$ values derived from the SeaDAS software (using the SeaDAS calibration coefficients and SeaDAS atmospheric correction) are highly underestimated at short wavelengths (blue). Large underestimations are also observed at other wavelengths due to the improper calibration coefficients. The SC calibration coefficients
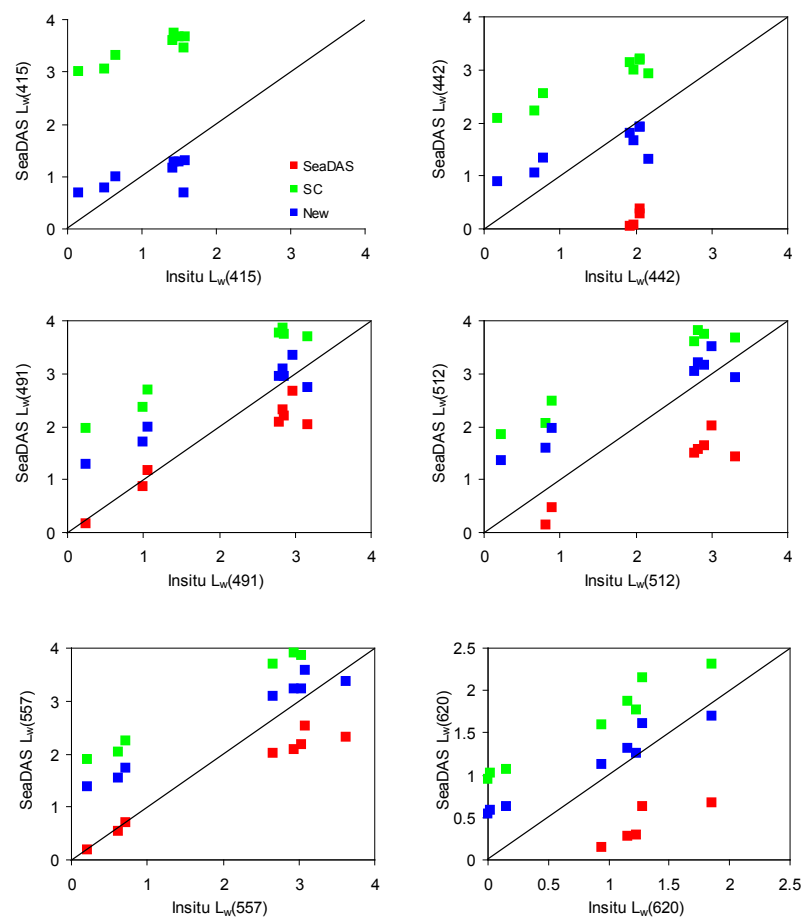

Figure 6: Scatterplots of the OCM-2 water-leaving radiance spectra derived from the SeaDAS atmospheric correction algorithm. SeaDAS, SC and new calibration coefficients were used to calibrate the OCM-2 data.
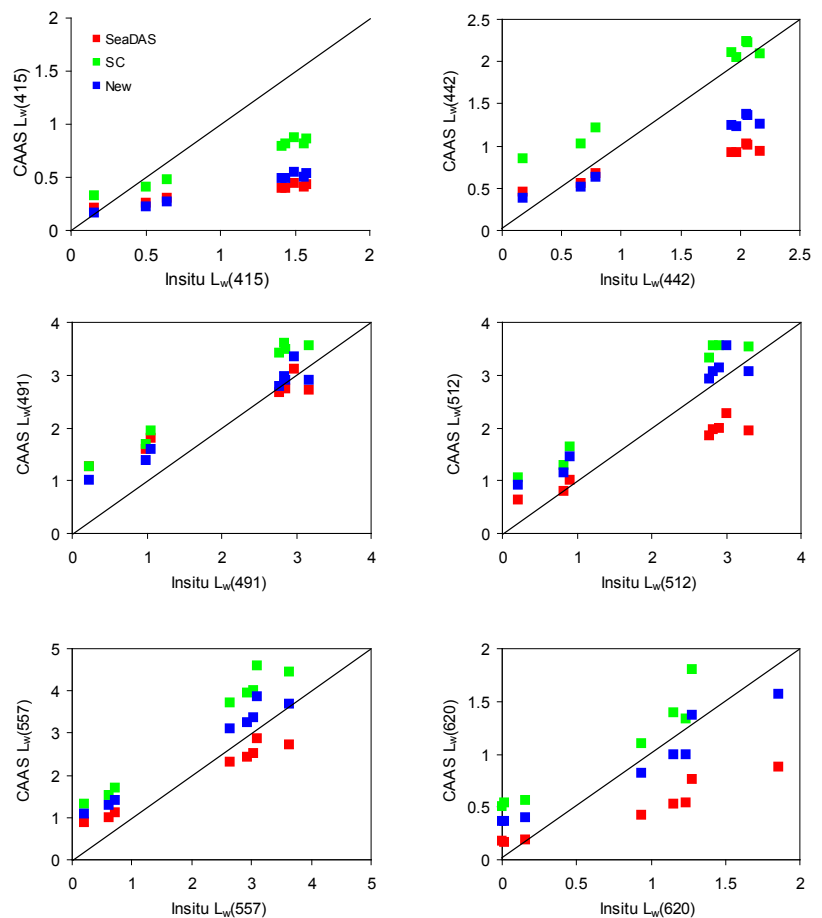

Figure 7: Scatterplots of the OCM-2 water-leaving radiance spectra derived from the CAAS atmospheric correction algorithm. SeaDAS, SC and new calibration coefficients were used to calibrate the OCM2 data.

produce very high $L_{w}(\lambda)$ values compared to the in-situ $L_{w}(\lambda)$ data. These discrepancies are notably removed when the new calibration coefficients are applied to the OCM-2 data. However, significant deviations are still present with this data (above the 1:1 line) which could be due to the atmospheric correction issues. Similar scatter plots of the OCM-2 water-leaving radiance spectra (for SeaDAS, SC and new calibration coefficients) derived from the CAAS atmospheric correction algorithm are shown in Figure 7. It is important to note that the new calibration coefficients applied with the CAAS atmospheric correction algorithm produce $\mathrm{L}_{\mathrm{w}}(\lambda)$ values that are closely consistent with in-situ $L_{w}(\lambda)$ data. Its underestimations of $L_{w}(\lambda)$ are however restricted to the blue channels (mainly $412 \mathrm{~nm}$ ), and this could be due to atmospheric correction error. These results suggest that the new calibration coefficients could be used along with CAAS algorithm to process OCM-2 data in coastal and bloom waters around India. Retrieval accuracies of $\mathrm{L}_{w}(\lambda)$ from the calibrated OCM-2 data (with the other two sets of calibration coefficients) are seemingly less remarkable compared to the previous results derived with the SeaDAS atmospheric correction algorithm. It should be noted that calibrations based on the inappropriate methods and atmospheric correction procedures would result in significant biases in the retrieved water-leaving radiance or reflectance measurements from satellites in such optically complex waters $[11,12]$.

\section{Conclusion}

In this paper, new calibration coefficients are determined for OCM-2 sensor through computation of the path radiance with a CAAS atmospheric correction scheme in coastal waters around India. The aim of this work was to provide a means for accurately retrieving waterleaving radiances from OCM-2 data in these coastal waters. The new calibration coefficients are different from those included in the SeaDAS 
Citation: Tholkapiyan M, Shanmugam P, Chauhan P, Suresh M (2012) Derivation of Calibration Coefficients for OCM-2 Sensor for Coastal Waters. J Geophys Remote Sensing 1:106. doi:10.4172/2169-0049.1000106

software and those provided with OCM-2 data (SC). The water-leaving radiance $\mathrm{L}_{\mathrm{w}}(\lambda)$ derived from OCM-2 data with these new calibration coefficients are found to be in good agreement with in-situ data, whereas the $\mathrm{L}_{w}(\lambda)$ values derived from these OCM-2 data with the SeaDAS and SC calibration coefficients are spectrally distorted and negatively biased in coastal waters off Point Calimere and in the Gulf of Mannar. When all these three sets of calibration coefficients are tested on several OCM2 data using SeaDAS and CAAS atmospheric correction algorithms, it is found that the performance of new calibration coefficients applied with the CAAS atmospheric correction algorithm is much better than that of the other two calibration coefficients applied with the SeaDAS atmospheric correction algorithm. The new calibration coefficients provides more reasonable $\mathrm{L}_{\mathrm{w}}(\lambda)$ retrievals in coastal waters and bloomdominated waters around India, whereas the SeaDAS and SC calibration coefficients provide erroneous results in these waters. The spectral shape and magnitude produced by the new calibration coefficients are also similar to those of in-situ $\mathrm{L}_{\mathrm{w}}(\lambda)$ data. These improved $\mathrm{L}_{\mathrm{w}}(\lambda)$ retrievals would allow for more accurate estimates of algal pigment concentrations and other properties in coastal waters around India using OCM-2 data.

\section{Acknowledgements}

This work was supported by IITM-ISRO cell under the grant (OEC0910129ISROPSHA). We are indebted to Mr. Rajasekhar and the Director of National Institute of Technology (NIOT) for providing the Sagar Purvi Coastal Research Vessel to carry out field sampling and radiometric measurements in coastal waters off Point Calimere and Gulf of Mannar in the Bay of Bengal. We thank Prof. N. Ramesh Babu and his team (Mr. G. Balaganesan and colleagues) for designing and fabricating a Cantilever platform for this application. We are thankful to the anonymous reviewers for their valuable comments, which helped to improve the content and structure of this manuscript.

\section{References}

1. Ohde T, Sturm B, Siegel H (2002) Derivation of SeaWiFS vicarious calibration coefficients using in situ measurements in Case 2 water of the Baltic Sea. Remote Sens Environ 80: 248-255.

2. Franz AF, Bailey SW, Werdell PJ, McClain CR (2007) Sensor-independent approach to the vicarious calibration of satellite ocean color radiometry. Applied Optics 46: 5068-5082.

3. Gordon HR (1997) Atmospheric correction of ocean colour imagery in the Earth Observing System era. J Geophys Res 102: 17081-17106.

4. Hooker SB, Esaias WE, Feldman GC, Gregg WW, McClain CR (1992) SeaWiFS Technical Report Series Vol 1: An overview of SeaWiFS, Ocean Colour. NASA Technical Memorandum.

5. Shanmugam $P$ (2012) CAAS: an atmospheric correction algorithm for remote sensing of complex waters. Annals Geophysicae 30: 203-220.

6. Austin RW (1974) Inherent spectral radiance signatures of the ocean surface Ocean Colour Analysis. La Jolla, CA Scripps Institute of Oceanography.

7. Mobley CD (1999) Estimation of the remote sensing reflectance from abovesea surface Measurements. Applied Optics 38: 7442-7455.

8. Ahn YH, Shanmugam P (2007) Derivation and analysis of the fluorescence algorithms to estimate phytoplankton pigment concentrations in optically complex coastal waters. Journal of Optics A: Pure and Applied Optics 9: $352-$ 362.

9. Shanmugam $P$ (2011) New models for retrieving and partitioning the coloured dissolved organic matter in the global ocean: Implications for remote sensing. Remote Sens Environ 115: 1501-1521.

10. Shanmugam P, Suresh M, Sundarabalan VB (2012) OSABT An innovative algorithm to detect and characterize surface algal blooms, In Press: IEEE Transaction on Selected Topics in Earth Observations and Remote Sensing.

11. Gerhard M, Franz BA, Kwiatkowska EJ, Charles RM (2012) Corrections to the Calibration of MODIS aqua Ocean colour bands derived from SeaWIFS Data. leee T Geosci Remote 50: 310-319.

12. Padmanava D, Nan W, Deepak M, Eurico D'Sa, Sherwin L (2012) Atmospheric Correction and Vicarious Calibration of Oceansat-1Ocean Colour Monitor (OCM) Data in Coastal Case 2 Waters. Remote Sens 4: 1716-1740. 